\title{
Regulation of NAD Biosynthesis in Salmonella typhimurium: Expression of nad-lac Gene Fusions and Identification of a nad Regulatory Locus
}

\author{
By ELIZABETH A. HOLLEY, MICHAEL P. SPECTOR \\ AND JOHN W. FOSTER* \\ Department of Microbiology, Marshall University School of Medicine, Huntington, \\ WV 25704, USA
}

(Received 24 July 1984; revised 29 November 1984)

\begin{abstract}
Regulation of NAD biosynthesis was examined through the construction of nad-lac fusions in Salmonella typhimurium. The nadA (17 unit map position) and nadB (55 units) genetic loci involved with quinolinic acid biosynthesis were both found to be regulated by the product of a $n a d R$ locus (99 units) in a repression/derepression manner while nadC (3 units) expression appeared constitutive at the transcriptional level. Increases in nad $A B$ transcription directly correlated with decreases in intracellular NAD(P) levels, and kinetic studies indicated that the NAD analogue 6-aminoNAD was ineffective in repressing either nad $A$ or nadB. The presence of cAMP + cAMP receptor protein was essential for the complete derepression of nadA while no effect was evident upon $n a d B$. Transfer of cultures from aerobic to anaerobic conditions, however, resulted in the partial derepression of both nad $A$ and nadB. Thus, there appears to be a very complex set of controls regulating NAD biosynthesis.
\end{abstract}

\section{INTRODUCTION}

The biosynthesis of NAD and NADP in Salmonella typhimurium includes a de novo pathway and a series of recycling and salvage pathways termed pyridine nucleotide cycles (Foster \& Moat, 1980). Four genes associated with de novo biosynthesis have been described for this enteric organism. They include nad $A$ at 17 units (Foster \& Moat, 1978; Langley \& Guest, 1974), $n a d B$ at 55 units (Foster \& Moat, 1978; Sanderson \& Roth, 1983), nadC at 3 units (Foster \& Moat, 1978; Langley \& Guest, 1974) and nadD at 14 units (Hughes et al., 1983a) on the $S$. typhimurium linkage map. The $\mathrm{Nad} A$ and $\mathrm{NadB}$ gene products comprise the quinolinic acid (QA) synthetase system, the $\mathrm{NadC}$ protein is quinolinic acid phosphoribosyltransferase (EC 2.4.2.19) and the NadD product is nicotinic acid mononucleotide adenylyltransferase (EC 2.7.7.18; Foster \& Moat, 1980; Hughes et al., 1983a, b). Fig. 1 illustrates the relationship between these genetic loci and NAD biosynthesis.

A powerful technique for examining gene expression involves the use of the mutagenic phage $\mathrm{Mu}$ cts dl (Ap $\mathrm{lac})$ constructed by Casadaban \& Cohen (1979). This phage contains an ampicillin resistance locus, a lac operon lacking a promoter and a temperature-sensitive phage repressor. When this phage is inserted in the proper orientation within a bacterial gene, expression of $\operatorname{lac} Z$ ( $\beta$-galactosidase) is controlled by the promoter of the inactivated gene. Thus, transcriptional control of the locus in question can be examined easily by monitoring $\beta$ galactosidase activity.

Preliminary results from our laboratory using a nadB-lac and a nadC-lac gene fusion constructed using Mud l suggested that transcription of nadB comes under repression control while $n a d C$ is transcribed constitutively (Holley \& Foster, 1982). In this report we describe the isolation of additional nadB-lac and nadC-lac fusions as well as nadA-lac gene fusions using

Abbreviations: NA. nicotinic acid; 6ANA, 6-aminonicotinic acid; QA, quinolinic acid; X-Gal, 5-bromo-4chloro-3-indolyl $\beta$-D-galactoside. 


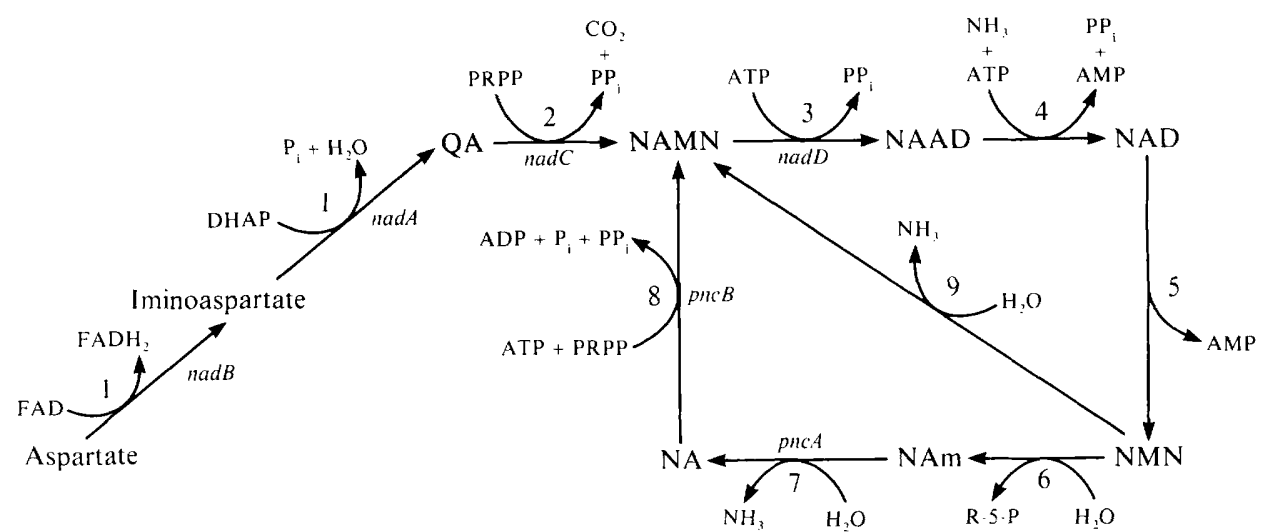

Fig. 1. NAD metabolism in Salmonella typhimurium and relationship of genetic loci to the pathway. DHAP, dihydroxyacetone phosphate. Enzymes: (1) Quinolinic acid (QA) synthetase; (2) QA phosphoribosyltransferase; (3) nicotinic acid mononucleotide (NAMN) adenylyltransferase: (4) NAD synthetase; (5) DNA ligase/NAD pyrophosphatase; (6) nicotinamide mononucleotide (NMN) glycohydrolase; (7) nicotinamide (NAm) deamidase; (8) nicotinic acid (NA) phosphoribosyltransferase; (9) NMN deamidase.

both the Mudl and the recently isolated Mud1-8 phage which requires an amber suppressor for transposition (Hughes \& Roth, 1984). Expression of these loci is characterized in terms of derepression/repression kinetics, pyridine nucleotide levels during derepression, the effect of various nad mutations on the expression of $n a d-l a c$ fusions, and the roles of oxygen and CAMP in $n a d A B$ regulon expression. In addition, the isolation of strains containing mutations (nad $R$ ) which alter nad $A B$ expression is described.

\section{METHODS}

Bacteria and phage. The bacterial strains used are derivatives of Salmonella typhimurium LT-2 (Table 1). The phage used were the high-transducing derivative of P22, HT105/1-int (Schmieger, 1971), Mucts dl (Ap ${ }^{r}$ lac) (Casadaban \& Cohen, 1979), also referred to as Mudl, and a derivative of Mudl designated Mu cts $\mathrm{d} 8\left(\mathrm{Ap} \mathrm{p}^{\mathrm{r}}\right.$ lac) or Mud1-8, constructed by Hughes \& Roth (1984) and kindly provided by them for our use.

Chemicals and reagents. All reagents were of analytical quality. 5-Bromo-4-chloro-3-indolyl $\beta$-D-galactoside (X-Gal), nicotinic acid (NA) and 6-aminonicotinic acid (6ANA) were purchased from Sigma.

Culture medium and conditions. The minimal E medium of Vogel \& Bonner (1956), supplemented with $0.4 \%$ glucose, was used throughout. Amino acids were supplemented at a concentration of $40 \mu \mathrm{g} \mathrm{ml}^{-1}$, uracil at $30 \mu \mathrm{g} \mathrm{ml}^{-1}$ and NA as described throughout the text. When used, ampicillin was added to $30 \mu \mathrm{g} \mathrm{ml}^{-1}$. Tetracycline was used-at $20 \mu \mathrm{g} \mathrm{ml}^{-1}$ in complex medium and $10 \mu \mathrm{g} \mathrm{ml}^{-1}$ in minimal media. Cultures were incubated at $30^{\circ} \mathrm{C}$ with shaking ( 175 r.p.m.) in a gyratory incubator. Anaerobic conditions were achieved in a $\mathrm{CO}_{2} / \mathrm{H}_{2}$ environment using the anaerobic Gas-Pak system (BBL). The anaerobic container was placed inside the gyratory shaker and shaken at 175 r.p.m. Anaerobic conditions were attained within $2 \mathrm{~h}$, as determined by a methylene blue indicator strip. Assays were performed 2-4 h later. Minimal lactose base medium was used when different carbon sources were examined (Foster et al., 1979).

Kinetic studies involved growing the strain to be tested overnight in supplemented minimal medium. Immediately prior to the study the culture was washed twice in minimal medium lacking glucose (E buffer) to remove any remaining NA. The washed culture was resuspended and used to inoculate the media described in the text.

\section{Table 1. Strains of S. typhimurium}




\section{Table 1 (continued)}

Strain

gal nadBl(0)l: : Mudl $\left(\mathrm{Lac}^{-}\right)$

JF296

JF297

JF 308

JF466

JF467

JF468

JF474

JF475

JF476

JF477

JF478

JF479

JF484

JF489

JF490)

JF491

JF508

JF536

JF596

JF627

JF630

JF632

JF 633

JF634

JF635

JF636

JF640

pyrD95 nadB I002:: Mudl $\left(\mathrm{Lac}^{+}\right)$

plrD95 arg:: Mudl ( $\left.\mathrm{Lac}^{+}\right)$

pirD95 nad (1003: : Mudl $\left(\mathrm{Lac}^{+}\right)$

pirD95 nadB l019:: Mud1 ( $\left.\mathrm{Lac}^{-}\right)$

plrD95 nadBl003: : Mudl (Lac $\left.{ }^{+}\right)$

pirD95 madC 1004:: Mudl (Lac $\left.{ }^{+}\right)$

pirD95 nadB 1005: : Mudl (Lac $\left.{ }^{+}\right)$

pirD95 nadC $1007:$ : Mudl $\left(\mathrm{Lac}^{+}\right)$

p.rD95 nadC loo8: : Mudl $\left(\mathrm{Lac}^{+}\right)$

prrD95 nadB I0(1) : : Mudl $\left(\mathrm{Lac}^{+}\right)$

plrD95 nadC 1010:: Mud1 $\left(\mathrm{Lac}^{+}\right)$

pirD95 madA 1011:: Mudl $\left(\mathrm{Lac}^{+}\right)$

pirD95 nadA 1011:: Mud1 nadB541:: Tn $/ 0$

p!rD95 nadB 1002: : : Mudl nadA540:: :Tn 10

pirD95 nadB B 1013:: Mud1 (Lac')

pirD95 nadB 10/4: : Mud1 $\left(\mathrm{Lac}^{-}\right)$

pyrD95 nadB 1015: : Mud1 (Lac $\left.{ }^{-}\right)$

purC7 proA46 il -405 rha-361 rpsL fla-56 pil =ff-30: :Tn 10 (Tn10 near nad $\left.B^{+}\right)$

trpA49 nadA56 pnc A15 $\wedge($ pmuA-nadR $) 1$

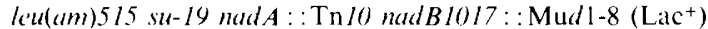

plrD 95 madB1002:: Mudl recAl srl-202:: Tn 10

pyrD95 nadA 1011: : Mudl tyra5

AnadBl20 nad $1011::$ Mudl plrD $95=f f-29:: \operatorname{Tn} 10$

AnadB122 nadA l011:: Mudl pirD95:ff-29:: Tn 10

AnadBI27 nadA I01/: : Mudl pirD95:ff-29:: Tn10

AhadB 130 nadA $1011::$ Mudl plrD $95=f f-29::$ Tn 10

pirD95 nadA I0Il:: Mudl tyrA5 recAl srl-202::Tn 10

pirD95 nadBlo02:: Mudl recAl srl-202:: Tn $10 / \mathrm{F}^{\prime} 142$ nadB $B^{+}$

pirD95 nadA 1011:: Mudl tyra5 recAl srl-202::Tn $10 / \mathrm{F}^{\prime} 142$ nad $B^{+}$

AnadC nadBlol7:: Mudl-8 (Ap lac $^{2}$

supD $D 0$

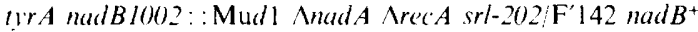

purC7 proA46 ile-405 rha-461 rpsL =ff-1909:: Tn 10 ( $\mathrm{Tn} 10$ near nadB $\left.{ }^{+}\right)$

$=f f-1000:: \mathrm{Mudl}-8$ purC7 proA46 ilt-405 rha-461 rpsL M10 fa-56 pil

=tf-190)9: :Tnlo nadBlo()2: : Mudl pirD95

$\Phi($ nadB-lac $) 1$ pyrD 95

pirD95 nadBl(0)2:: Mudl (ya: :Tn 10

pirD95 nadA I0II:: Mudl cra::Tn 10

pirD95 nadBlo02: : : Mudl c $\mathrm{l} a:: \operatorname{Tn} 10 \mathrm{crp}^{*}$

p!rD95 nadAl0/l::Mudl cya::Tn $/ 0$ crp*

pirD95 nadA 1011:: Mudl tira5 recAl srl-202: : Tn $10 / \mathrm{F}^{\prime} 152$ nad $A^{+}$

$\Phi($ nadB-lac $) 1$ nadRI pyrD95

$z f f-28:: \operatorname{Tn} 10$ nadRI prrDS5 (Tn10 near nadB $\left.{ }^{+}\right)$

nadB 1017:: Mud1-8 z\#f-28:: Tn10 nadRI plrD95

nad A 1011:: Mud 1 p!rD95 $\operatorname{nadR2}$

nadA I0ll : : Mud1 pirDS5 nadR3

nad $A 540:: \operatorname{Tn} 10$ nadR 2 p!rD 95

nadA540:: $\mathrm{Tn} 10$ nad 2 nadB $1017::$ Mud $1-8$

typa 49 nad 56 pnc A I5 $\Lambda($ pmuA nadR $)$ nadB $1017::$ Mudl-8

nadA56 pnc A15 pmiA7 trpA49 madB1017:: Mud1-8

mudA56 pncA15 pmuAll trpA49 nadB/017::Mud1-8

nadA56 =ji-1004::Tn10 pnc $15 \operatorname{trpA49}\left(\operatorname{Tn} 10\right.$ near $\left.p n u A^{+}\right) \quad$ J. Roth

his D9953:: Mudl-8 J. Roth

i $a:: \operatorname{Tn} 10 \operatorname{trp} B 223$

P. Postma

$\mathrm{SF} 142$

SF 145

plrD34 trp-45 his-68 tyra2 recAl thi-l galK35 xyl-7 mtl-2 rpsL/18 $\lambda^{-} \lambda^{\mathrm{k}} / \mathrm{F}^{\prime} 142$

B. Bachmann

EK2 (KL709) (E. coli)

EK62

pirD34 trp-45 his-68 tirA2 recal thi-l galK35 malal ry-7 mil-2 rpsLlls $\lambda^{-} \lambda^{k} / F^{\prime} 152 \operatorname{nad} A^{+}(\dot{E}$. coll $)$

B. Bachmann

* J. Roth, Department of Biology, University of Utah, Salt Lake City, Utah, USA; P. Postma, BCP Jansen Instituut, University of Amsterdam, The Netherlands; B. Bachmann, E. coli Genetic Stock Center, Yale University, New Haven, Conn., USA. 
Construction of gene fusions. Mud-directed gene fusions were constructed in a manner similar to that described earlier (Holley \& Foster, 1982). HT phage propagated either on a Mudl lysogen (JF296) or on a Mud1-8 lysogen (SF142) were used to introduce $\mathrm{Mud}$ into $\mathrm{nad}^{+}$recipients. Two methods of screening for $\mathrm{Nad}^{-}$auxotrophs were used. The first method involved the direct plating of phage and cells on LB medium containing ampicillin. Resultant Ap $\mathrm{p}^{\mathrm{r}}$ colonies were replicated to minimal medium containing ampicillin either with or without $10^{-5} \mathbf{M}^{-}$ NA. NA-requiring mutants (nad: : Mud) were purified and tested for the lac ${ }^{+}$characteristic on minimal medium containing X-Gal. Alternatively, nad:: Mud fusions were enriched using cycloserine selection. Cells and phage $\left(0.25 \mathrm{ml}\right.$ each) were mixed and incubated stationary for $1 \mathrm{~h}$ at $30^{\circ} \mathrm{C}$. After the addition of fresh minimal medium $(5.0 \mathrm{ml})$, ampicillin was added to $30 \mu \mathrm{g} \mathrm{ml}^{-1}$ and the culture incubated overnight at $30^{\circ} \mathrm{C}$ with shaking. The overnight culture was washed twice and resuspended to $10^{7}$ cells $\mathrm{ml}^{-1}$ in $100 \mathrm{ml}$ minimal medium. Cycloserine was added to $1 \mathrm{~mm}$ when the culture attained a density of $2 \times 10^{8}$ cells ml-1. After clearing (approximately $1-1.5 \mathrm{~h}$ ), the culture was washed twice and resuspended in $10 \mathrm{ml}$ minimal medium containing ampicillin and NA. This was allowed to grow overnight. The overnight culture was diluted and plated onto minimal medium supplemented with NA. Resultant colonies were then screened for their NA requirement by replicating onto medium with and without NA. Potential nad: : Mud strains were analysed as described above. $\beta$-Galactosidase activity was assayed on all fusion strains as described by Miller (1972), and is expressed as Miller units. Values given represent means of two or more independent experiments.

Genetic manipulations. Conjugations and transductions were done by mixing donor cells or phage with recipient cells directly on selective medium. Transductants were screened for nonlysogens on green medium as described by Chan et al. (1972). Tn 10-generated deletions were selected on the medium described by Maloy \& Nunn (1981) with some modification. Depending upon the strain, Maloy \& Nunn medium was formulated using lower quantities of tryptone, usually one-half to one-quarter the normal amount. Mud-directed deletions were constructed by selecting for either $\mathrm{Lac}^{+} \mathrm{Ap}^{s} \mathrm{Ts}^{+}$or $\mathrm{Lac}^{-} \mathrm{Ap}^{\mathrm{s}} \mathrm{Ts}^{+}$colonies as described by Maloy \& Roth (1983). All deletions were checked by crosses with known point mutations. Point mutations were made using the hydroxylamine comutagenesis procedure described by Hong \& Ames (1971).

Construction of a pool of Mudl-8 insertions. Since Mudl-8 will not transpose unless it is present in a supD background, it was possible to use $\mathrm{Mud} 1-8$ to construct a pool of insertions in manner similar to that commonly used for Tn10. P22 phage grown on a Mud1-8 lysogen (SF142) was used to infect a supD strain (JF706). The resulting Apr colonies $(\sim 2000)$, comprising a Mudl-8 transposition pool, were collected in approximately $2 \mathrm{ml}$ saline containing $15 \%(\mathrm{v} / \mathrm{v})$ glycerol. A $0.5 \mathrm{ml}$ sample of these cells was grown to mid-exponential phase in $500 \mathrm{ml}$ LB and infected with P22. After overnight incubation, $200 \mathrm{ml}$ of the phage preparation was harvested and the supernatant lysate used for subsequent screening of Mud1-8 insertions near nadB.

Measurement of NAD and NADP concentrations. Pyridine nucleotides were measured using cold $40 \%(\mathrm{v} / \mathrm{v})$ acetic acid extraction of $\left[{ }^{1+} \mathrm{C}\right] \mathrm{NA}$-labelled nucleotides as described previously (Foster et al., 1979). Cells were grown overnight in supplemented minimal medium, washed to remove unlabelled NA and resuspended in fresh minimal medium containing $10^{-5} \mathrm{M}$ - or $10^{-7} \mathrm{M}-\left[{ }^{1+} \mathrm{C}\right] \mathrm{NA}\left(10 \mu \mathrm{Ci} \mu \mathrm{mol}^{-1} ; 370 \mathrm{kBq} \mu \mathrm{mol}^{-1}\right)$. Samples were filtered, washed with cold $E$ buffer and the intracellular nucleotides extracted with $0.5 \mathrm{ml}$ cold $40 \%(\mathrm{v} / \mathrm{v})$ acetic acid. An equal volume of extract for each strain was chromatographed on an isobutyric acid/ammonium hydroxide $/ \mathrm{H}_{2} \mathrm{O}$ $(66: 1: 33$, by vol.) solvent system.

\section{RESULTS AND DISCUSSION}

\section{Isolation, characterization and expression of nad-lac fusions}

$\mathrm{Mu} d \mathrm{l}\left(\mathrm{Ap}^{\mathrm{r}} l a c\right)$ - and $\mathrm{Mu} d \mathrm{l}-8\left(\mathrm{Ap}^{\mathrm{r}} l a c\right)$-directed $l a c Z$ fusion strains were isolated as described in Methods using either direct isolation or cycloserine enrichment. All independently isolated $A \mathrm{p}^{r}$ NA-requiring strains were mapped to the nadA, the $\operatorname{nadB}$ or the nadC locus by transducing the fusion strain to $\operatorname{nad}^{+}$using phage propagated on known nadA (JF28), nadB (JF22) or nadC (JF29) mutants. Failure of a particular phage preparation to repair the nad::Mud insertion indicated the nad locus into which the fusion had occurred. Scoring of ad $^{+}$transductants for the loss of $\mathrm{Ap}^{\mathrm{r}}$ and the acquisition of temperature resistance was used to indicate the presence of a single Mud insertion in the nad locus. Table 2 lists the $n a d::$ Mud insertions isolated and presents the results of in vitro $\beta$-galactosidase activities obtained following growth in various concentrations of NA. The results indicate that the nadA fusion and five of the $10 \operatorname{nad} B$ fusions are controlled at the transcriptional level by end-product repression. The $\operatorname{nad} B:$ : Mud insertions which exhibit low unregulated $\beta$-galactosidase activities probably represent $\mathrm{Mu} d$ insertions in the wrong orientation for transcription from the nadB promoter. Transcription of nadC is constitutive in nature (Table 2). 
Table 2. Expression of various nad: : Mud fusions

\begin{tabular}{|c|c|c|c|c|}
\hline \multirow[b]{2}{*}{ Strain } & \multirow[b]{2}{*}{$\begin{array}{l}\text { Pertinent } \\
\text { genotype }\end{array}$} & \multicolumn{3}{|c|}{$\beta$-Galactosidase activity } \\
\hline & & $10^{-+} \mathrm{M}-\mathrm{NA}$ & $10^{-7} \mathrm{M}-\mathrm{NA}$ & $\begin{array}{l}\text { Increase } \\
\text { (fold) }\end{array}$ \\
\hline JF478 & $\operatorname{nad} A 1011:$ : Mud 1 & $54 \cdot 75$ & 819 & 15 \\
\hline JF 153 & $\operatorname{nadB1001}:$ : Mud1 & $0 \cdot 0$ & $0 \cdot 0$ & - \\
\hline JF295 & $\operatorname{nadB} 1002:: \mathrm{Mud} 1$ & $18 \cdot 8$ & 395 & 21 \\
\hline JF308 & $\operatorname{nadB1019}:$ :Mud I & $0 \cdot 0$ & $0 \cdot 0$ & - \\
\hline JF466 & nadB1003: : Mudl & $1 \cdot 2$ & $6 \cdot 1$ & $5 \cdot 1$ \\
\hline JF468 & $\operatorname{nadB1005}:$ :Mud1 & $27 \cdot 6$ & 703 & 25 \\
\hline JF476 & nadBlo09: : Mudl & $1 \cdot 0$ & $1 \cdot 24$ & - \\
\hline JF489 & nadB1013::Mud1 & $3 \cdot 38$ & $2 \cdot 72$ & - \\
\hline JF490 & $\operatorname{nadB1014}:$ :Mud1 & $41 \cdot 8$ & 701 & 17 \\
\hline JF491 & nadB1015::Mud1 & $1 \cdot 56$ & $1 \cdot 2$ & - \\
\hline JF596 & $n a d B 1017:: \mathrm{Mud} 1-8$ & 11.5 & 361 & 33 \\
\hline JF297 & 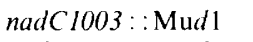 & 37 & 21 & - \\
\hline JF467 & $\operatorname{nadC} 1004:$ : Mud1 & $2 \cdot 3$ & $2 \cdot 7$ & - \\
\hline JF474 & $\operatorname{nad}(1007:: \mathrm{Mud} 1$ & $2 \cdot 19$ & $2 \cdot 32$ & - \\
\hline JF475 & nadC $1008:$ :Mudl & 6.7 & 5.5 & - \\
\hline JF477 & $\operatorname{nad} C 1010:: \mathrm{Mud} 1$ & 3.65 & 3.71 & - \\
\hline
\end{tabular}

Kinetics of nad $A-l a c Z$ and nadB-lac $Z$ expression

Strains JF478 (nadA::Mud1) and JF295 (nadB::Mud1) were examined more precisely during NA starvation to determine at what point derepression of these genes occurs and how this derepression is related to internal pyridine nucleotide concentrations. A parallel culture was used for the labelling of internal pyridine nucleotides. The results are shown in Figs 2 and 3. Both nad $A$ and $n a d B$ were derepressed at approximately the same time, $1-1.5 \mathrm{~h}$ after transfer to $10^{-7} \mathrm{M}-\mathrm{NA}$. During this period the total pyridine nucleotide content declined to $0.6-0.7 \mathrm{~mm}$ (Fig. 3). $\mathrm{NAD}(\mathrm{H})$ decreased from its normal value of $0.9 \mathrm{~mm}$ to $0.5 \mathrm{~mm}$ while $\mathrm{NADP}(\mathrm{H})$ decreased from $0.3 \mathrm{~mm}$ to $0.15 \mathrm{~mm}$. Similar values for intracellular pyridine nucleotides were reported by Bochner \& Ames (1982). These data illustrate the direct relationship between internal pyridine nucleotide concentrations and the expression of the nadAB regulon. The NADP $(\mathrm{H}) / \mathrm{NAD}(\mathrm{H})$ ratio, while remaining constant at $0.32-0.34$ during balanced growth, rose dramatically during NA starvation. The increase probably reflects a need in the stressed cell to maintain NADP $(\mathrm{H})$ levels for biosynthetic purposes. Alternatively, the increased ratio may represent a signal which affects the expression of the NAD biosynthetic genes. A similar effect was observed with Escherichia coli by Lundquist \& Olivera (1973).

\section{Repression kinetics and the effect of $6 A N A$ on nad $A-l a c Z$ and nadB-lacZ expression}

The addition of NA or nicotinamide to a growing $n a d-l a c Z$ fusion strain results in the repression of nadA and $\operatorname{nadB}$, presumably through conversion to NAD. To determine how quickly external pyridine sources can generate a repression signal (i.e. increased internal NAD levels) the experiments presented in Fig. 4 were performed. Both nadA-lacZ (JF478) and nadBlacZ (JF295) fusion strains were grown overnight in $10^{-4} \mathrm{M}$-NA-supplemented minimal medium. After washing twice in $\mathrm{E}$ buffer, the cells were transferred to a starvation medium containing $10^{-6} \mathrm{M}$-NA to derepress $\operatorname{nad} A$ and $\operatorname{nadB}$. Growth, and the increase in $\beta$-galactosidase activity, were monitored during derepression. At the time indicated, the culture was split into three subcultures; one received $\mathrm{NA}\left(10^{-4} \mathrm{M}\right)$, another received the analogue 6ANA $(4 \times$ $\left.10^{-4} \mathrm{M}\right)$ and the third received no addition. Addition of NA had an immediate effect in stopping the derepression of both $\operatorname{nad} A$ and $\operatorname{nadB}$ (Fig. 4). The subculture containing the NA analogue, however, appeared to show an increased derepression of these genes for 75-90 min (at which point growth was affected). The delay observed with the analogue does not appear to be the result of a lower rate of uptake and utilization since we and others (Hughes et al., 1983b) have 

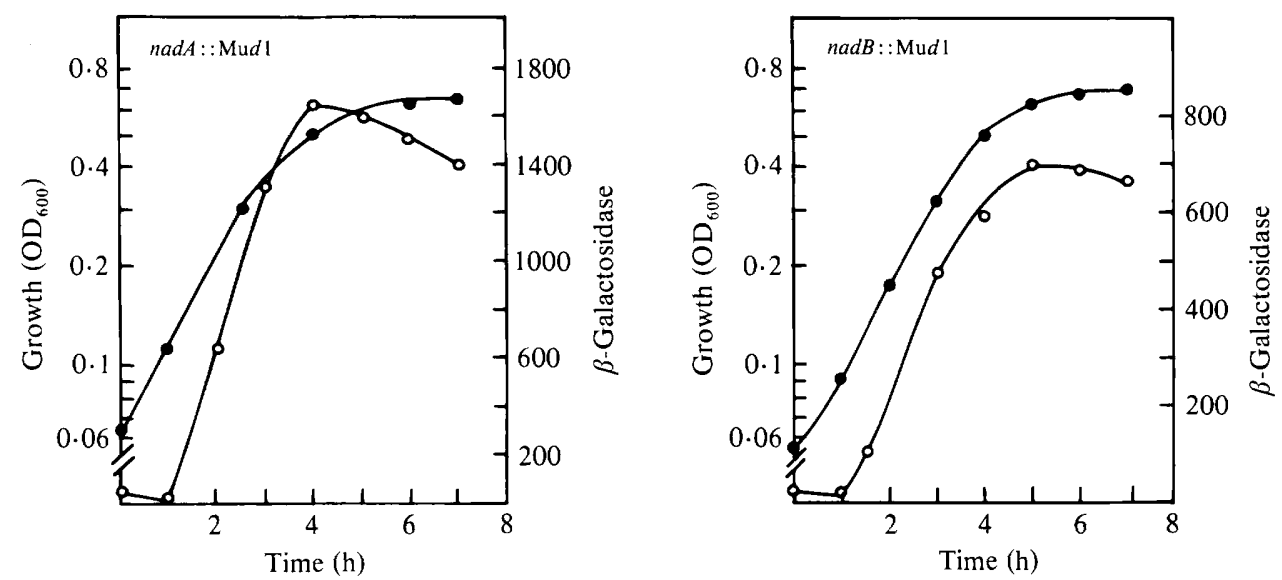

Fig. 2. Kinetics of nad-lac derepression. Cultures of strains JF478 (nadA::Mudl) and JF295 ( $\operatorname{nad} B:: \mathrm{Mud} 1$ ) were transferred from $10^{-5} \mathrm{M}-\mathrm{NA}$ to $10^{-7} \mathrm{M}-\mathrm{NA}$ at time zero. $\mathrm{O}$, Growth; $\bigcirc, \beta$ galactosidase activity (Miller units).

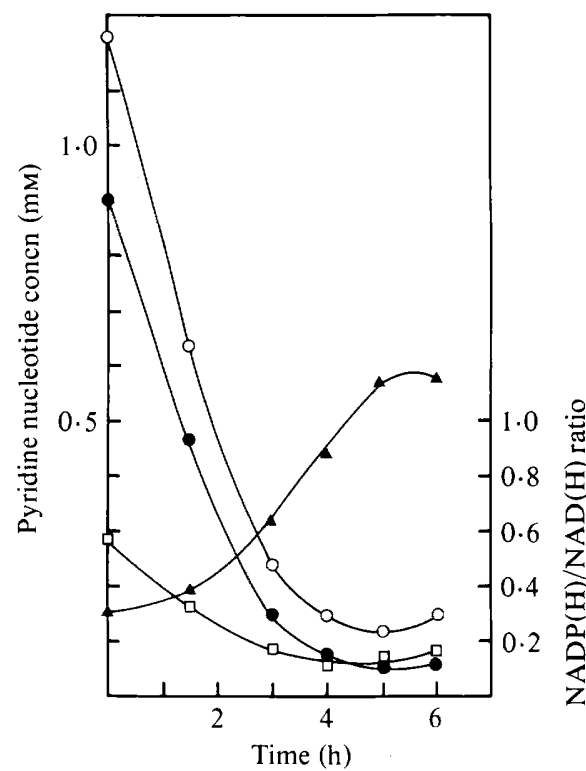

Fig. 3. Pyridine nucleotide concentrations during NA starvation. Strain JF478 (nadA::Mud1), after overnight growth in $10^{-5} \mathrm{M}-\left[{ }^{1+} \mathrm{C}\right] \mathrm{NA}$, was washed and transferred to $10^{-7} \mathrm{M}-\left[{ }^{14} \mathrm{C}\right] \mathrm{NA}$. Samples were taken and analysed for intracellular pyridine nucleotides as described in Methods. $\bigcirc$, Total pyridine nucleotide concentration; $\boldsymbol{O}$, NAD $(\mathrm{H}) ; \square, \mathrm{NADP}(\mathrm{H}) ; \boldsymbol{\Delta}, \mathrm{NADP}(\mathrm{H}) / \mathrm{NAD}(\mathrm{H})$ ratio.

found that the addition of analogue to unstarved cells results in an increase of intracellular 6aminoNAD concentrations within $10-15 \mathrm{~min}$ after addition. Our results indicate that 6aminoNAD does not represent a repression signal for nad $A$ or $n a d B$. The initial increase in $\beta$ galactosidase is most probably due to the accelerated depletion of NAD levels which has been shown to occur following the administration of these analogues (Hughes et al., 1983b).

All the data presented above indicate that $\operatorname{nad} A$ and $\operatorname{nad} B$ are controlled at the transcriptional level by a repression-derepression mechanism. Saxton et al. (1968) and Chandler \& Gholson (1972) have presented data suggesting repression control of this system in E. coli. The present study, however, is the first to demonstrate unequivocally in either E. coli or $S$. typhimurium that this regulation occurs at the transcriptional level. 

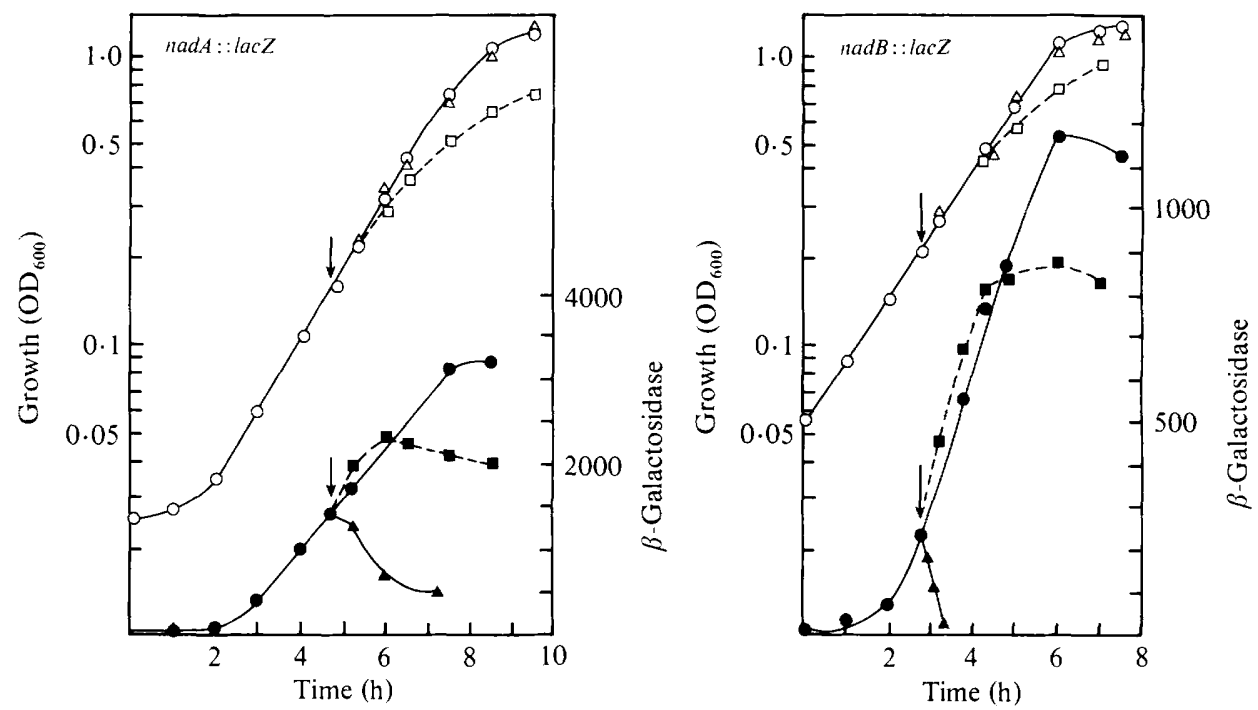

Fig. 4. Repression kinetics of nad-lac fusion strains JF478 (nadA::lacZ) and JF295 (nadB::lacZ) grown with NA or 6ANA. Derepression was initially accomplished in $10^{-6} \mathrm{M}-\mathrm{NA}$. Vertical arrows indicate the time of addition. $O$, Growth with no addition; $\square$, growth with $4 \times 10^{-4} \mathrm{M}-6 \mathrm{ANA} ; \triangle$, growth with $10^{-4} \mathrm{M}-\mathrm{NA} ; \boldsymbol{O}, \beta$-galactosidase (Miller units) with no addition; $\boldsymbol{\square}, \beta$-galactosidase with $4 \times 10^{-4} \mathrm{M}-6 \mathrm{ANA} ; \boldsymbol{\Delta}, \beta$-galactosidase with $10^{-4} \mathrm{M}-\mathrm{NA}$.

Table 3. Effect of nad mutations on the expression of nad-lac fusions in haploids and merodiploids

\begin{tabular}{|c|c|c|c|c|}
\hline \multirow[b]{2}{*}{ Strain } & \multirow[b]{2}{*}{ Pertinent genotype } & \multicolumn{3}{|c|}{$\beta$-Galactosidase activity } \\
\hline & & $10^{-+} \mathrm{M}-\mathrm{NA}$ & $10^{-7} \mathrm{M}-\mathrm{NA}$ & $\begin{array}{l}\text { Increase } \\
\text { (fold) }\end{array}$ \\
\hline $\mathrm{JF} 478$ & nad $A 101 /:: \mathrm{Mud} 1$ & $54 \cdot 7$ & 819 & $15 \cdot 0$ \\
\hline JF479 & nadA1011:: Mud1 nadB541::Tn10 & $55 \cdot 1$ & 726 & $13 \cdot 2$ \\
\hline JF295 & 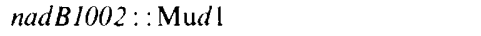 & $60 \cdot 0$ & 765 & $12 \cdot 8$ \\
\hline $\mathrm{JF} 484$ & 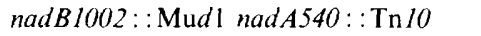 & $75 \cdot 0$ & 990 & $13 \cdot 2$ \\
\hline JF698 & 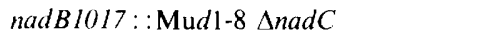 & $12 \cdot 6$ & 347 & $27 \cdot 5$ \\
\hline $\mathrm{JF} 627$ & $\operatorname{nadB1002}:: \mathrm{Mud} 1$ & $60 \cdot 1$ & 712 & $11 \cdot 9$ \\
\hline $\mathrm{JF} 640$ & $\operatorname{nadB} 1002:: \mathrm{Mud} 1 / \mathrm{F}^{\prime} 142 \mathrm{nadB}^{+}$ & $80 \cdot 9$ & 239 & $2 \cdot 9$ \\
\hline $\mathrm{JF} 714$ & $\operatorname{nadB} 1002:$ :Mud 1 AnadA $/ \mathrm{F}^{\prime} 142$ nadB $B^{+}$ & $67 \cdot 3$ & 842 & $12 \cdot 5$ \\
\hline JF636 & $\operatorname{nadA1011}:$ :Mudl & $54 \cdot 8$ & 927 & $16 \cdot 9$ \\
\hline JF641 & $\operatorname{nadA} 1011:: \mathrm{Mud} 1 / \mathrm{F}^{\prime} 142 \operatorname{nadB}^{+}$ & $80 \cdot 8$ & 1309 & $16 \cdot 2$ \\
\hline
\end{tabular}

\section{Regulation and merodiploid studies}

Reports suggest the presence of a regulatory locus in $E$. coli, designated nadR, adjacent to $n a d B$; mutations in this locus appeared to decrease the amount of both $\mathrm{NadA}$ and $\mathrm{NadB}$ protein (Tritz \& Chandler, 1973). It was unclear, however, whether nad $R$ actually represented a class of nad $B$ mutant affecting some autoregulatory feature of the nadB gene product (Foster \& Moat, 1980). To answer this question in $S$. typhimurium we constructed a series of strains containing either a nadA-lac fusion and a nadB::Tn 10 insertion (JF479) or a nadB-lac fusion and a nad $A:: \operatorname{Tn} 10$ insertion (JF484). Presumably if the $n a d B$ gene product regulated its own expression as well as that of $\mathrm{nad} A$ then the insertion of $\mathrm{Tn} 10$ into nadB should eliminate control over nad $A-l a c Z$ expression. The data presented in Table 3 reveal that this is not the case. Thus, the $\operatorname{nad} R$ locus, if it exists, is not allelic with $\operatorname{nadB}$.

To determine if $n a d R$ was situated adjacent to $n a d B$ we isolated a series of $\operatorname{Tn} 10$ and $\mathrm{Mud} 1-8$ insertions near $n a d B$ for the purpose of generating deletions through $\operatorname{nad} B$. Certainly if $\operatorname{nad} R$ occupied a position next to $\operatorname{nadB}$, some Tn10- or Mud-generated deletions should remove $\operatorname{nad} R$ 
and render nadA-lacZ expression constitutive. Numerous $n a d B$ deletions were transferred to JF478 or constructed in JF479 (nadA : : Mud nadB : :Tn10) as described in Methods. Screening for the $n a d R$ phenotype involved plating the potential deletions on minimal medium containing $\mathrm{X}$-Gal supplemented with $10^{-5} \mathrm{M}$ or $5 \times 10^{-7} \mathrm{M}-\mathrm{NA}$. None of the deletions appeared altered with respect to regulation (data not shown). These results suggest that $\operatorname{nad} R$, at least in $S$. typhimurium, is probably not situated near nadB.

Merodiploid studies were done to determine if the E. coli nadA and nadB loci could complement the analogous loci of $S$. typhimurium. $\mathrm{F}^{\prime} 142\left(\right.$ nadB $\left.B^{+}\right)$and $\mathrm{F}^{\prime} 152\left(\right.$ nad $\left.^{+}\right)$were transferred to several of the fusion strains constructed during this study. The results (Table 3 ) reveal that $\mathrm{F}^{\prime} 142$ does complement a chromosomal nadB mutation (JF640) but does not appear to have an effect upon nadB-lacZ (JF714) or nadA-lacZ (JF641) expression as long as a requirement for NA is maintained. Strain JF640, which no longer requires NA for growth, does not show as great a level of $n a d B-l a c Z$ derepression. This can be explained by the fact that the merodiploid can maintain intracellular NAD concentrations through de novo synthesis. Similar results were obtained with nadA merodiploids. Studies with $E$. coli indicate that the NadB protein complexes with the NadA protein to form an active QA synthetase (Nasu et al., 1982). The fact that the $\mathrm{F}^{\prime}$ strains used in this study were derived from $E$. coli strongly suggests that the $\mathrm{NadB}$ and $\mathrm{NadA}$ proteins of $S$. typhimurium also form a complexed QA synthetase in which an $E$. coli $\mathrm{NadB}$ or NadA protein can substitute for the missing Salmonella component.

\section{Isolation of nadR mutants altered in nadAB regulon expression}

A stabilized nadB-lac fusion strain (JF797) would not grow on minimal medium containing lactose as the sole carbon source if a repressive concentration of $\mathrm{NA}\left(10^{-4} \mathrm{M}\right)$ was included. This strain was heavily streaked on this same medium containing X-Gal as an indicator in the hope that spontaneous nadR mutations would result in the constitutive expression of the nadB-lac fusion. The subsequent overproduction of $\beta$-galactosidase would allow growth on minimal lactose medium containing a repressive concentration of NA.

Several strains were isolated by this method. In order to determine if the mutation occurred in a locus separate from $\operatorname{nadB}$ (i.e. $n a d R$ ) each strain was transduced to $n a d B^{+}$prototrophy and checked for loss of the $\mathrm{Lac}^{+}$characteristic. Next a $\operatorname{nad} B:: \mathrm{Mud} 1-8$ insertion was reintroduced and expression analysed. Three of the regulatory mutants initially isolated were apparently altered in the $n a d B$ region since reintroduction of $n a d B::$ Mud $1-8$ resulted in normal repressiondepression of $n a d B$. One strain, however, upon reintroduction of nadB::Mud1-8 still produced $\beta$-galactosidase constitutively (Table 4). Similar nadR mutations were isolated in a nadA-lac fusion strain. These, too, caused deregulation of $n a d B$-lac fusions (Table 4). The results indicate that the nadA and nadB loci form a regulon controlled by nadR.

\section{Map position of nadR}

Each of the nadR mutants was crossed with phage propagated on strains containing $\operatorname{Tn} 10$ insertions near various NAD-related loci. In each instance, the $n a d R$ mutation was found to map near pnu $A$ (pyridine nucleotide uptake) at 99 units (Table 5). This clearly indicates that nad $R$ is not located at $n a d B$ as suggested for $E$. coli and that the nadR gene product probably acts in trans upon nadA and nadB. Spector et al. (1985) have shown that nadR mutations also affect the regulation of $p n u C$. It would appear that $n a d R$ is distinct from $p n u A$. Several pnuA point mutations had no effect upon $n a d B-l a c Z$ repression (Table 6). However, a pnuA deletion clearly resulted in the constitutive expression of $\operatorname{nad} B$, suggesting that $\operatorname{nad} R$ is situated very close to pnuA (Table 6).

\section{Effect of nadR on intracellular NAD concentrations}

To determine if the nadR regulatory mutation also altered pyridine nucleotide cycle metabolism the nadB-lac nadRI strain JF864 and its nad $R^{+}$parent JF797 were used for in vivo labelling experiments with $\left[{ }^{1+} \mathrm{C}\right] \mathrm{NA}$. Both strains were grown overnight in supplemented minimal medium, washed twice to remove unlabelled NA and then used to inoculate minimal medium supplemented with $\left[{ }^{1+} \mathrm{C}\right] \mathrm{NA}$ at $10^{-5} \mathrm{M}$. Periodic samples were taken and intracellular 
Table 4. Effect of nadR on nadA and nadB expression

\begin{tabular}{|c|c|c|c|}
\hline \multirow[b]{2}{*}{ Strain } & \multirow[b]{2}{*}{ Pertinent genotype } & \multicolumn{2}{|c|}{$\beta$-Galactosidase activity } \\
\hline & & $10^{-+} \mathrm{M}-\mathrm{NA}$ & $10^{-6} \mathrm{M}-\mathrm{NA}$ \\
\hline JF797 & $\Phi(\operatorname{nad} B \operatorname{lac} Z)$ & $18 \cdot 4$ & 320 \\
\hline JF864 & $\Phi($ nadB-lac $Z)$ nadRl & 667 & 680 \\
\hline JF867 & $\operatorname{nad} B^{+} \operatorname{nadRI}$ & $0 \cdot 0$ & $0 \cdot 0$ \\
\hline JF868 & $\operatorname{nad} B:: \mathrm{Mud} I-8 \operatorname{nad} I$ & 868 & 921 \\
\hline $\mathrm{JF} 478$ & $\operatorname{nad} A:: \mathrm{Mud}]$ & $48 \cdot 3$ & 1194 \\
\hline JF903 & $\operatorname{nad} A:: \mathrm{Mud} 1 \operatorname{nad} R 2$ & 1296 & 1336 \\
\hline JF905 & $\operatorname{nad} A^{+} \operatorname{nad} R 2$ & $0 \cdot 0$ & $0 \cdot 0$ \\
\hline JF906 & $\operatorname{nad} B:: \mathrm{Mud} 1-8 \operatorname{nad} R 2$ & 849 & 930 \\
\hline
\end{tabular}

Table 5. Cotransduction of nadR to zjj-1004::Tn10 (Tn10 near pnuA $\left.A^{+}\right)$

Donor phage was grown on SF71. Initial selection was for $\mathrm{Tet}^{\mathrm{k}}$.

$\begin{array}{clcc}\text { Recipient } & \text { Pertinent genotype } & \begin{array}{c}\text { Number } \\ \text { scored }\end{array} & \left.\begin{array}{c}\text { Linkage to } \\ z j j-1004:: \operatorname{Tn} l 0(\%)\end{array}\right) \\ \text { JF864 } & \Phi(\text { nadB lac) nadRI } & 95 & 81 \\ \text { JF903 } & \text { nad } A: \text { : Mudl nadR2 } & 106 & 46 \\ \text { JF904 } & \text { nadA : : Mudl nadR3 } & 99 & 30\end{array}$

Table 6. Effect of pnuA mutations on nadB-lac expression

\begin{tabular}{|c|c|c|c|c|}
\hline \multirow[b]{2}{*}{ Strain } & \multirow[b]{2}{*}{ Pertinent genotype } & \multicolumn{3}{|c|}{$\beta$-Galactosidase activity } \\
\hline & & $10^{-4} \mathrm{M}-\mathrm{NA}$ & $10^{-6} \mathrm{M}-\mathrm{NA}$ & $\begin{array}{l}\text { Increase } \\
\text { (fold) }\end{array}$ \\
\hline JF596 & nad $B::$ Mudll-8 & $18 \cdot 5$ & 441 & 24 \\
\hline JF985 & $\Lambda p n u A$ nadB : : Mudl1-8 & 801 & 661 & - \\
\hline JF992 & $p m u A 7 n a d B:: \operatorname{Mudl-8}$ & $22 \cdot 2$ & 312 & 14 \\
\hline JF993 & phuA / / nadB : : MudI-8 & $18 \cdot 4$ & 473 & 26 \\
\hline
\end{tabular}

nucleotides extracted with cold $40 \%(\mathrm{v} / \mathrm{v})$ acetic acid. Chromatography was performed in several solvent systems. The results (not shown) suggested no significant difference between intracellular $\left[{ }^{1+} \mathrm{C}\right] N A D$ levels of the nad $R$ mutant as compared with the nad $R^{+}$control. Samples were taken at comparable cell densities. Previous studies have indicated that the intracellular NADP/NAD ratio remains relatively constant at $0 \cdot 3-0 \cdot 34$ during exponential growth (Foster \& Moat, 1980; Lundquist \& Olivera, 1973; Foster et al., 1984). Our results confirmed this, with a ratio of $0 \cdot 33$.

\section{Effect of carbon source and anaerobiosis on nad-lac expression}

The isolation of nad-lac fusions and the construction of a nadB-lac/F' $\mathrm{F}^{\prime}$ adB $B^{+}$strain (JF640) allowed the evaluation of carbon source and oxygen supply on the regulation of NAD biosynthesis at the transcriptional level. Preliminary experiments revealed that the nadBlac $/ \mathrm{F}^{\prime}$ nad $B^{+}$strain, with no NA requirement, expressed $\beta$-galactosidase at a constant level during exponential growth. Thus, analyses of conditions resulting in different growth rates could be compared. Table 7 presents the $\beta$-galactosidase activities obtained after growth on glucose, glycerol and acetate under aerobic conditions and on glucose under anaerobic conditions. The data indicate that regardless of the carbon source and subsequent growth rate nadB is expressed at a relatively constant level. However, transfer of the culture to anaerobic conditions resulted in at least a twofold derepression of $\beta$-galactosidase, suggesting an increased requirement for NAD under anaerobiosis. Similarly, transfer of a $\operatorname{nadA}-\mathrm{lac} / \mathrm{F}^{\prime}$ nad $A^{+}$strain to anaerobic conditions resulted in a threefold increase in $\beta$-galactosidase. These results were very reproducible. 
Table 7. Effect of carbon source and oxygen on nad lac expression

\begin{tabular}{|c|c|c|c|c|c|}
\hline Strain & $\begin{array}{l}\text { Pertinent } \\
\text { genotype }\end{array}$ & Carbon source & Atmosphere & $\begin{array}{c}\text { Generation } \\
\text { time } \\
(\mathrm{min})\end{array}$ & $\begin{array}{c}\beta \text {-Galactosidase } \\
\text { activity }\end{array}$ \\
\hline JF640 & $\operatorname{nadB}-l a c / \mathbf{F}^{\prime} \operatorname{nad} B^{+}$ & $\begin{array}{l}\text { Glucose }(30 \mathrm{~mm}) \\
\text { Glycerol }(50 \mathrm{mM}) \\
\text { Acetate }(50 \mathrm{mM}) \\
\text { Glucose }(30 \mathrm{mM})\end{array}$ & $\begin{array}{l}\text { Aerobic } \\
\text { Aerobic } \\
\text { Aerobic } \\
\text { Anaerobic }\end{array}$ & $\begin{array}{r}75 \\
170 \\
460 \\
140\end{array}$ & $\begin{array}{l}213 \\
208 \\
216 \\
424\end{array}$ \\
\hline JF836 & $\operatorname{nad} A-\operatorname{lac} / \mathrm{F}^{\prime} \operatorname{nad} A^{+}$ & $\begin{array}{l}\text { Glucose }(30 \mathrm{~mm}) \\
\text { Glucose }(30 \mathrm{~mm})\end{array}$ & $\begin{array}{l}\text { Aerobic } \\
\text { Anaerobic }\end{array}$ & $\begin{array}{r}70 \\
145\end{array}$ & $\begin{array}{r}307 \\
1107\end{array}$ \\
\hline
\end{tabular}

Table 8. Effect of adenyl cyclase and cAMP on nad-lac expression

Cells were inoculated to an initial $\mathrm{OD}_{600}$ of $0 \cdot 06$; $\mathrm{cAMP}$ was added at $\mathrm{OD}_{600} 0.2$ and $\beta$-galactosidase activity measured at $\mathrm{OD}_{600} 0 \cdot 6$.

\begin{tabular}{|c|c|c|c|c|c|}
\hline Strain & Pertinent genotype & $\begin{array}{l}\text { NA } \\
\text { concn } \\
(\mathrm{M})\end{array}$ & $\begin{array}{c}\text { cAMP } \\
\text { concn } \\
(\mathrm{M})\end{array}$ & Activity & $\frac{\text { osidase }}{\begin{array}{c}\text { Increase } \\
\text { (fold) }\end{array}}$ \\
\hline JF478 & $\operatorname{nadA1011}: \mathrm{Mud1}$ & $\begin{array}{l}10^{-4} \\
10^{-4} \\
10^{-6} \\
10^{-6}\end{array}$ & $\begin{array}{l}- \\
5 \\
- \\
5\end{array}$ & $\begin{array}{r}58 \\
62 \\
1039 \\
1077\end{array}$ & $\begin{array}{l}17 \cdot 9 \\
18 \cdot 6\end{array}$ \\
\hline JF802 & $\begin{array}{l}\text { nadA } 1011:: \mathrm{Mud} 1 \\
\text { cla: :Tn } 10\end{array}$ & $\begin{array}{l}10^{-4} \\
10^{-4} \\
10^{-6} \\
10^{-6}\end{array}$ & $\begin{array}{l}- \\
5 \\
- \\
5\end{array}$ & $\begin{array}{r}62 \\
59 \\
331 \\
813\end{array}$ & $\begin{array}{r}5 \cdot 4 \\
13 \cdot 2\end{array}$ \\
\hline JF804 & $\begin{array}{c}\text { nad } A 1011:: \mathrm{Mud} 1 \\
\text { cva: :Tn } 10 \text { crp }^{*}\end{array}$ & $\begin{array}{l}10^{-4} \\
10^{-6}\end{array}$ & $\begin{array}{l}- \\
-\end{array}$ & $\begin{array}{r}37 \\
726\end{array}$ & $19 \cdot 6$ \\
\hline JF295 & $\operatorname{nadB} 1002:: \mathrm{Mu} d 1$ & $\begin{array}{l}10^{-4} \\
10^{-4} \\
10^{-6} \\
10^{-6}\end{array}$ & $\begin{array}{l}- \\
5 \\
- \\
5\end{array}$ & $\begin{array}{r}29 \\
32 \\
760 \\
703\end{array}$ & $\begin{array}{l}26 \\
24\end{array}$ \\
\hline JF801 & 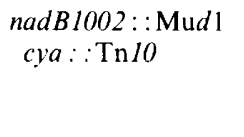 & $\begin{array}{l}10^{-4} \\
10^{-4} \\
10^{-6} \\
10^{-6}\end{array}$ & $\begin{array}{l}- \\
5 \\
- \\
5\end{array}$ & $\begin{array}{r}40 \\
36 \\
549 \\
553\end{array}$ & $\begin{array}{l}13 \cdot 8 \\
13 \cdot 8\end{array}$ \\
\hline JF803 & 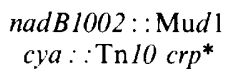 & $\begin{array}{l}10^{-4} \\
10^{-6}\end{array}$ & $\begin{array}{l}- \\
-\end{array}$ & $\begin{array}{r}19 \\
293\end{array}$ & $15 \cdot 4$ \\
\hline
\end{tabular}

This phenomenon is not due to some anaerobic effect on $\beta$-galactosidase since several other fusions isolated in our laboratory were unaffected by the presence or absence of oxygen. Wimpenny \& Firth (1972) have reported that when E. coli is switched to anaerobic conditions NAD concentrations drop precipitously and then rise slowly. This would explain the increase in $n a d B$ expression demonstrated here. The reported drop in NAD concentration could be related to the oxygen requirement reported by Nasu et al. (1982) for $\operatorname{nadB}$.

The tight control exerted over QA synthetase and thus NAD biosynthesis was also evident in these studies. Merodiploids grown in medium containing various carbon sources resulting in a wide range of growth rates nevertheless expressed $\operatorname{nadB}$ at a constant level. Studies with Pseudomonas aeruginosa have revealed that $\mathrm{NAD}(\mathrm{H})$ concentrations remain relatively constant on a wide variety of carbon sources (Martin \& Gottschal, 1976). The constant level of nadB-lac expression in Salmonella suggests a similar consistency in NAD $(\mathrm{H})$ levels. Transfer to anaerobic conditions, however, resulted in a definite, reproducible two- to threefold increase in nad-lac expression. 


\section{Role of $C A M P$ in the expression of nadA}

Various nutrient limitations, including phosphate, ammonia and glucose, were tested for their effects on the expression of the nad $A B$ regulon. Only glucose starvation resulted in an observable increase in $\beta$-galactosidase activity of nad $A$ fusion strains. The effect was evident on solid media but could not be demonstrated in liquid media (data not shown).

One obvious possible signal molecule suggested by the glucose limitation study is cAMP. Thus, a $c y a:: \operatorname{Tn} 10$ insertion was introduced into the nadA-lac and nadB-lac fusion strains to prevent $\mathrm{cAMP}$ synthesis and $\beta$-galactosidase production was measured during NA starvation conditions. The results presented in Table 8 show that nad $A$ expression was dependent upon adenylate cyclase and cAMP while the effect was not evident with $\operatorname{nad} B$. Derepression of $\operatorname{nad} A$ was greatly reduced in a $c y a:: \operatorname{Tn} 10$ background but was increased upon the addition of $5 \mathrm{mM}$ cAMP. Additionally, a nadA-lac cya : : Tn 10 strain containing a $c r p^{*}$ mutation, which codes for a cAMP receptor protein that does not require cAMP for activity, displayed normal derepression. This phenomenon has been demonstrated in a second, independent nadA-lac operon fusion strain (data not shown).

The results presented in this communication suggest dual regulation of nad $A$ : by NAD levels through nadR repression and by cAMP and its receptor protein (which are apparently required for full derepression). The reason for this cAMP-dependence is not immediately apparent. However, it is interesting that nadB does not appear to display this dual regulation. Further studies of the nad $A B$ regulon at the molecular level will be necessary to determine precisely the various levels of regulation and reveal other potential signal molecules involved with controlling NAD biosynthesis.

We thank K. Hughes and J. Roth for kindly providing the Mud1-8 phage derivative for our use. This work was supported by Public Health Service grant I ROI GM 32595.

\section{REFERENCES}

Bochner, B. R. \& AmEs, B. N. (1982). Complete analysis of cellular nucleotides by two dimensional thin layer chromatography. Journal of Biological Chemistry 257, 9759-9769.

Casadaban, M. J. \& Cohen, S. N. (1979). Lactose genes fused to exogenous promotors in one step using a $\mathrm{Mu}$-lac bacteriophage: in vico probe for transcriptional control sequences. Proceedings of the National Academy of Sciences of the United States of America 76, 4530-4533.

Chan, R. K., Botstein, D., Watanabe, T. \& Ogata, Y. (1972). Specialized transduction of tetracycline resistance by phage P22 in Salmonella typhimurium. II. Properties of a high frequency transducing lysate. Virology 50, 883-898.

Chandler, J. L. R. \& Gholson. R. K. (1972). De noto biosynthesis of nicotinamide adenine dinucleotide in Escherichia coli: excretion of quinolinic acid by mutants lacking quinolinate phosphoribosyl transferase. Journal of Bacteriology 111, 98-102.

Foster, J. W. \& Moat, A. G. (1978). Mapping and characterization of the nad genes in Salmonella typhimurium LT-2. Journal of Bacteriology 133, 775 779.

Foster, J. W. \& Moat, A. G. (1980). Nicotinamide adenine dinucleotide biosynthesis and pyridine nucleotide cycle metabolism in microbial systems. Microbiological Retiens 44, 83-105.

Foster, J. W., Kinney, D. M. \& Moat, A. G. (1979). Pyridine nucleotide cycle of Salmonella typhimurium: isolation and characterization of pnc $A, p n c B$ and pnc $C$ mutants and utilization of exogenous nicotin- amide adenine dinucleotide. Journal of Bacteriology 137, 1165-1175.

Foster, J. W., Holley, E. A. \& MYA, S. (1984). NAD metabolism in Salmonella typhimurium: isolation of pyridine analogue supersensitive (pas) and pas suppressor mutants. Journal of General Microbiology 130, 2873-2881.

Holley, E. A. \& Foster, J. W. (1982). Bacteriophage P22 as a vector for Mu mutagenesis in Salmonella typhimurium: isolation of nad-lac and pnc-lac gene fusions. Journal of Bacteriology' 152, 959-962.

HoNG, J. S. \& AMES, B. N. (1971). Localized mutagenesis of any specific small regions of the bacterial chromosome. Proceedings of the National Academy of Sciences of the United States of America 68, $3158-3162$

Hughes, K. T. \& Roth, J. R. (1984). Conditionally transposition-defective derivative of Mudl (Amp Lac). Journal of Bacteriology 159, 130-137.

Hughes, K. T., Ladika, E., Roth, J. R. \& Olivera, B. M. $(1983 a)$. An indispensable gene for NAD biosynthesis in Salmonella typhimurium. Journal of Bacteriology 155, 213-221.

Hughes, K. T., CoOkson, B. T., Ladika, D., Olivera, B. M. \& RoTH, J. R. (1983b). 6-Aminonicotinamideresistant mutants of Salmonella typhimurium. Journal of Bacteriology 154, 1126-1136.

LANGley, D. \& Guest, J. R. (1974). Biochemical and genetic characteristics of deletion and other mutant strains of Salmonella typhimurium LT-2 lacking $\alpha$ keto acid dehydrogenase complex activities. Journal of General Microbiology 82, 319-335. 
Lundquist, R. \& Olivera, G. M. (1973). Pyridine nucleotide metabolism in Escherichia coli. II. Niacin starvation. Journal of Biological Chemistry 248, 5137 5143.

Maloy, S. R. \& NunN, W. D. (1981). Selection for loss of tetracyctine resistance by Escherichia coli. Journal of Bacteriology 145, 1110-1112.

Maloy, S. R. \& Roth, J. R. (1983). Regulation of proline utilization in Salmonella typhimurium: characterization of put:: Mud(Ap, lac) operon fusions. Journal of Bacteriology 154, 561-568.

Martin, A. \& GotTSCHaL, J. C. (1976). Influence of dilution rate on $\mathrm{NAD}(\mathrm{P})$ and $\mathrm{NAD}(\mathrm{P}) \mathrm{H}$ concentrations and ratios in a Pseudomonas sp. grown in continuous culture. Journal of General Microbiology 94, 333--341.

Miller, J. H. (1972). Experiments in Molecular Genetics. Cold Spring Harbor, NY: Cold Spring Harbor Laboratory.

NASU, S., Wicks, F. D. \& Gholson, R. K. (1982). LAspartate oxidase, a newly discovered enzyme of Escherichia coli, is the B protein of quinolinate synthetase. Journal of Biological Chemistry 257, 626 632.

SANDERSon, K. E. \& Roth, J. R. (1983). Linkage map of Salmonella typhimurium, edition VI. Microbiological Reviews 47, 410-453.
Saxton, R. E., Rocha, V., Rosser, R. J., ANDreoli, A. J., Shimoyoma, M., Sosska, A., Chandler, J. L. R. \& Gholson, R. K. (1968). A comparative study of the regulation of nicotinamide adenine dinucleotide biosynthesis. Biochimica et biophysica acta 156, 77-84

SCHMIEGER, H. (1971). A method for detection of phage mutants with altered transducing ability. Molecular and General Genetics 110, 378 381.

Spector, M. P., Hill, J., Holley, E. A. \& Foster, J. W. (1985). Genetic characterization of pyridine nucleotide uptake mutants of Salmonella typhimurium. Journal of General Microbiology 131, 1313 - 1322.

Tritz, G. J. \& Chandler, J. L. R. (1973). Recognition of a gene involved in the regulation of nicotinamide adenine dinucleotide biosynthesis. Journal of Bacteriology 114, 128136.

Vogel, H. J. \& Bonner, D. M. (1956). Acetyl ornithinase of Escherichia coli: partial purification and some properties. Journal of Biological Chemistry 93, 237-244.

WimpenNy, J. W. T. \& FirTh, A. (1972). Levels of nicotinamide adenine dinucleotide and reduced nicotinamide adenine dinucleotide in facultative bacteria and the effect of oxygen. Journal of Bacteriology 111, 24-32. 